\title{
EVALUASI ERGONOMI KOKPIT PESAWAT UDARA N-219 DENGAN USABILITY TESTING
}

\section{N-219 AIRPLANE'S COCKPITERGONOMICS EVALUATION USING USABILITY TESTING}

\author{
Triyono Widi Sasongko ${ }^{a}$, Nina Kartika ${ }^{\text {a }}$, Tegar Septyan ${ }^{\text {b, }}$ \\ Dimas Bahtera $E^{a}$, Budi Sampurno ${ }^{c}$ \\ ${ }^{a}$ Pusat Teknologi Sistem dan Prasarana Transportasi BPPT \\ ${ }^{b}$ Departemen Teknik Industri Fakultas Teknik UI \\ ${ }^{c}$ Program N-219 PT Dirgantara Indonesia \\ e-mail: triyono.widi@bppt.go.id
}

\begin{abstract}
Abstrak
Analisis optimalisasi ergonomi kokpit pesawat udara N-219 sangat penting untuk dilakukan, dikarenakan postur tubuh yang kaku disebabkan oleh konfigurasi kokpit yang kurang baik membuat pilot merasa tidak nyaman, cepat lelah yang akan menyalahi keamanan penerbangan dan berbahaya bagi pilot. Hasil survey pengukuran ergonomic kognitif dengan metode pengukuran usability dengan Questionnaire for User Interaction Satisfaction (QUIS), yang meliputi reaksi aircrew terhadap keseluruhan slstem, display, teknologi slstem informasi, pembelajaran dan kapabilitas slstem di kokpit N-219 mempunyai nilai pada skala 7,32 hingga 8,19, dengan kategori baik dan bisa diterima, meskipun terdapat beberapa kekurangan yang harus diperbaiki.Dalam pengembangan selanjutnya, kokpit perlu didesain ulang untuk bisa mengakomodasi pilot yang memiliki tubuh di atas rata-rata karena secara umum sistem yang berjalan saat ini masih kurang nyaman bagi pilot yang memiliki persentil atas.
\end{abstract}

Kata Kunci : Ergonomi, Kokpit N-219, Usability Test

\begin{abstract}
Analysis of optimization of the airplane's cockpit ergonomics N-219 is very important to do, due to the rigid posture caused by the uncomfortable of configuration of the cockpit thatmake pilots uneasy and tired. It is going to violate the security of the flight and dangerous for pilots. The survey results of measurement with the method of measurement of cognitive ergonomic usability with a Questionnaire for User Interaction Satisfaction (QUIS), which includes reaction to the overall system, aircrew display systems technology, information, learning and capability systems in the cockpit N-219 has a value on a scale of 7.32 up to 8.19, by category which is good and acceptable, although there were some shortcomings that must be rectified.In future development, cockpit needs to be redesigned to be able to accommodate the pilots who have above average of anthropometric because in general the system running at present still less convenient for pilots who have the top percentile.
\end{abstract}

Keywords : Cockpit Ergonomics, N-219, Usability Test

Diterima (received ) : 14 Oktober 2017, Direvisi (revised) : 09 November 2017 Disetujui (Accepted) : 30 November 2017 


\section{PENDAHULUAN}

Saat ini PT. Dirgantara Indonesia sedang melakukan pengembangan pesawat udara $\mathrm{N}$ 219 yang memiliki kelebihan dibandingkan pesawat kompetitornya yaitu memiliki volume kabin yang lebih besar, multi purpose, dapat lepas landas dan mendarat pada landasan sepanjang 450 meter. Landasan tidak harus beraspal atau beton tetapi juga lapangan berumput dan memiliki kapasitas angkut lebih besar $500 \mathrm{~kg}$ dari pesawat kompetitor lainnya.

Dalam rangka pengembangan pesawat $\mathrm{N}-219$ diperlukan analisis optimalisasi ergonomi konfigurasi kokpit pesawat terhadap rancangan yang sudah ada, untuk mendukung keselamatan penerbangan. Konfigurasi kokpit yang nyaman bagi pilot merupakan syarat untuk meningkatkan keamanan dan menjamin pilot dalam kondisi yang baik.

Tujuan dari penelitian ini adalah untuk memperoleh optimalisasi ergonomi konfigurasi kokpit pesawat udara N-219 agar pilot merasa nyaman dan aman saat mengemudikan pesawat sehingga akan menjamin keselamatan penerbangan.

Pada tahun 2016 telah dilakukan perhitungan ergonomic fisik seperti LBA(Low Back Analysis), OWAS(Ovako Working Posture Analysis), RULA(Rapid Upper Limb Assessment)terkait dengan gerakan pilot dalam mengemudi dan menjangkau, serta jangkauan pandangan mata ${ }^{1}$. Beberapa hasil adalah sebagai berikut:

a) Berdasarkan perhitungan nilai LBA yang menunjukkan tekanan kompresi yang dialami oleh tubuh didapatkan jangkauan nilai sebesar 256 - 574 Newton. Hal ini masih berada di bawah nilai batas toleransi yang sebesar 3400 Newton, yang merupakan batas nilai beban ideal untuk punggung yang dapat diterima oleh manusia. Dari hasil perhitungan LBA untuk persentil bawah dan atas ini menunjukkan bahwa postur kerja untuk bagian punggung masih memenuhi batas normal.

b) Nilai OWAS pada gerakan mengemudi dan menjangkau menunjukkan nilai 1 yang berarti masih berada dalam toleransi

c) Pada analisis RULA ditemukan bahwa gerakan menjangkau ini adalah postur kritis karena memiliki nilai RULA yang lebih besar dibandingkan gerakan mengemudi.

d) Untuk analisis jangkauan mata masih berada dalam jangkauan normal baik untuk ke arah depan maupun pada saat ke arah bawah
Untuk melengkapi hasil di atas, maka pada paper ini akan disampaikan hasil analisis ergonomik kognitif dengan pengukuran usabilitas terhadap aspek ergonomi kokpit $\mathrm{N}-219$ dengan cara mewawancarai pilot dan flight engineer. Ergonomi kognitif berkaitan dengan proses mental, seperti persepsi, memori, penalaran, dan respon motorik yang mempengaruhi interaksi manusia dan bagian lain dari sistem $6,7)$

\section{METODOLOGI}

$\begin{array}{ccc}\text { Metodeusability } & \text { testingdalam evaluasi } \\ \text { ergonomi } & \text { kognitif dilakukan dengan }\end{array}$ melakukan wawancara kepada para pilot dan flight engineer $\mathrm{N}-219$ dengan panduan pertanyaan, sehingga responden dapat melakukan penilaian mandiri terhadap beberapa aspek ergonomi kokpit pesawat $\mathrm{N}$ 219 yang dikenal dengan Questionnaire for User Interaction Satisfaction (QUIS).

UsabilitymenurutISO FDIS 9241210dapat didefinisikan sebagai seberapa jauh sebuah sistem, produk atau jasa bisa digunakan oleh pengguna tertentu untuk mencapai tujuan yang spesifik dengan efektif, efisien, dan memuaskan dalam konteks penggunaan. Menurut Nielsen (1993) dalam bukunya yang berjudul Usability Engineering ${ }^{2)}$, ada lima dimensi utama yang harus diperhatikan yaitu:

- Learnability (pembelajaran), sebuah sistem harus dapat dipelajari dengan mudah dan cepat agar pengerjaan dari tujuan yang diinginkan dapat diselesaikan.

- Efficiency (efisiensi), berkaitan dengan produktivitas, begitu pengguna sistem telah selesai mempelajari sistem diharapkan dapat meingkatkan tingkat produktivitas.

- Memorability (pengingatan), sebuah sistem harus dapat diingat oleh pengguna dengan baik, bahkan apabila pengguna sudah lama tidak menggunakan sistem tersebut dan tanpa harus mempelajari seluruh sistem tersebut dari awal lagi.

- Errors (kesalahan), sebuah sistem harus memiliki tingkat kesalahan yang rendah sehingga apabila pengguna sedang menggunakan sistem dan berbuat kesalahan, maka pengguna dapat dengan mudah memperbaiki kesalahan tersebut.

- Satisfaction (kepuasan), sistem yang baik juga harus dapat menyenangkan bagi penggunanya 
Evaluasi Ergonomi Kokpit Pesawat Udara N-219 Dengan Usability Testing (Triyono Widi Sasongko, Nina Kartika, Tegar Septyan, Dimas Bahtera E, Budi Sampurno)

QUIS merupakan kuesioner yang digunakan sebagai alat pengukuran kepuasan subjektif pengguna terhadap aspek human-computerinterface. QUIS mulai dikembangkan pada tahun 1987 oleh University of Maryland Human-Computer Interaction Lab. QUIS terdiri dari 27 pertanyaan yang dibagi menjadi 5 kategori yaitu Overall Reaction to The Software, Screen, Terminology and System Information, Learning dan System Capabilities. Pada setiap pertanyaannya memiliki piihan jawaban dengan skala $0-9^{4}$.

Berdasarkan hasil-hasil studi sebelumnya terkait usabilitas ${ }^{2,3,5)}$ jumlah optimal yang efisien untuk responden adalah sebesar 3-5 untuk menemukan sekitar 75$85 \%$ terkait masalah usabilitas.

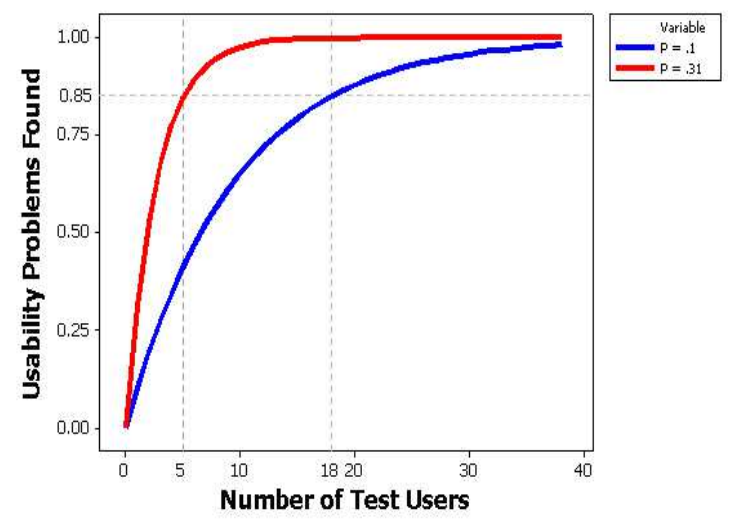

Gambar 1.

Jumlah Sampel dalam Usability Testing

Pada tahap ini akan dianalisis hasil survey terhadap 5 orang aircrew (2 pilot dan 3 flight engineer) menggunakan metode QUIS dengan melihat 5 aspek utama yaitu reaksi keseluruhan terhadap sistem, layar, terminologi dan sistem informasi, pembelajaran, dan kapabilitas sistem.

\section{HASIL DAN PEMBAHASAN}

\section{Data Kokpit N-219}

Kokpit N-219 dioperasikan oleh dua pilot, pilot duduk disebelah kiri dan bertanggung jawab terhadap keamanan pesawat selama penerbangan, sedangkan kopilot duduk disebelah kanannya dan bertugas membantu pilot. Kontrol dan display yang berada didalam kokpit dan bersifat sering dan penting digunakan selama penerbangan harus bisa dioperasikan dari sisi pilot maupun dari sisi kopilot. Dalam keadan darurat, misalnya salah satu pilot pingsan, pesawat harus bisa dikendalikan dengan aman sampai ke landasan. Kokpit N-219 terdiri dari Instrument Panel/Forward Panel, Glareshield Panel,Center Console, Overhead Panel, danCircuit Breaker Panel. Sedangkan Forward Panel itu sendiri terdiri dari Pilot Forward Panel, Copilot Forward Panel dan Center Forward Panel).

Pilot/Copilot Forward panel berada tepat didepan pilot/kopilot dan masing masing berisi satu buah Primary Flight Display yang identik.Primary Flight Display berfungsi menampilkan informasi penting yang dibutuhkan saat terbang dan harus sering dipantau selama penerbangan.

Center Forward Panel berada diantara Pilot/kopilot Forward Panel. Kontrol dan display yang berada di area panel ini harus bisa dipantau dan dioperasikan oleh kedua pilot. Center Forward Panel terdiri dari Multi Function Display.Peletakan panel didesain agar pilot dapat memonitor dan mengakses area panel tanpa halangan saat mereka sedang bertugas. Pada sisi kanan dan kiri di bagian bawah instrument panel terpasang berbagai macam kontrol.

Pada bagian bawah Forward Pane/ berisi kontrol dari berbagai sistem yang dibutuhkan pesawat seperti: sistem elektrik, sistem fuel, dan lain-lain. Kontrol di area ini umumnya hanya dioperasikan sebelum pesawat lepas landas, dan dilakukan oleh masing-masing pilot yang terdekat dengan kontrol tersebut.

Glareshield Panel berada tepat diatas Forward Panel dan berfungsi untuk menjaga semua display yang berada dibawahnya bebas dari silau yang diakibatkan cahaya dari luar kokpit. Kontrol atau display yang berada di panel ini harus bisa dipantau dan dioperasikan oleh kedua pilot. Panel ini terdiri dari Auto Pilot Kontrol Panel.

Center console berisi kontrol yang sering dioperasikan selama operasi penerbangan seperti powerplant control dan flight control. Panel kontrol yang berada di area ini harus dapat dijangkau oleh kedua pilot dengan mudah.

Overhead Panel berada tepat diatas pilot dan kopilot dan hanya berisi dome light dan outlet pendingin ruang.Sedangkan Circuit Breaker Panel berada di samping kiri dan kanan dinding center console.Panel ini tidak pernah dioperasikan/dipantau selama pesawat di udara. 


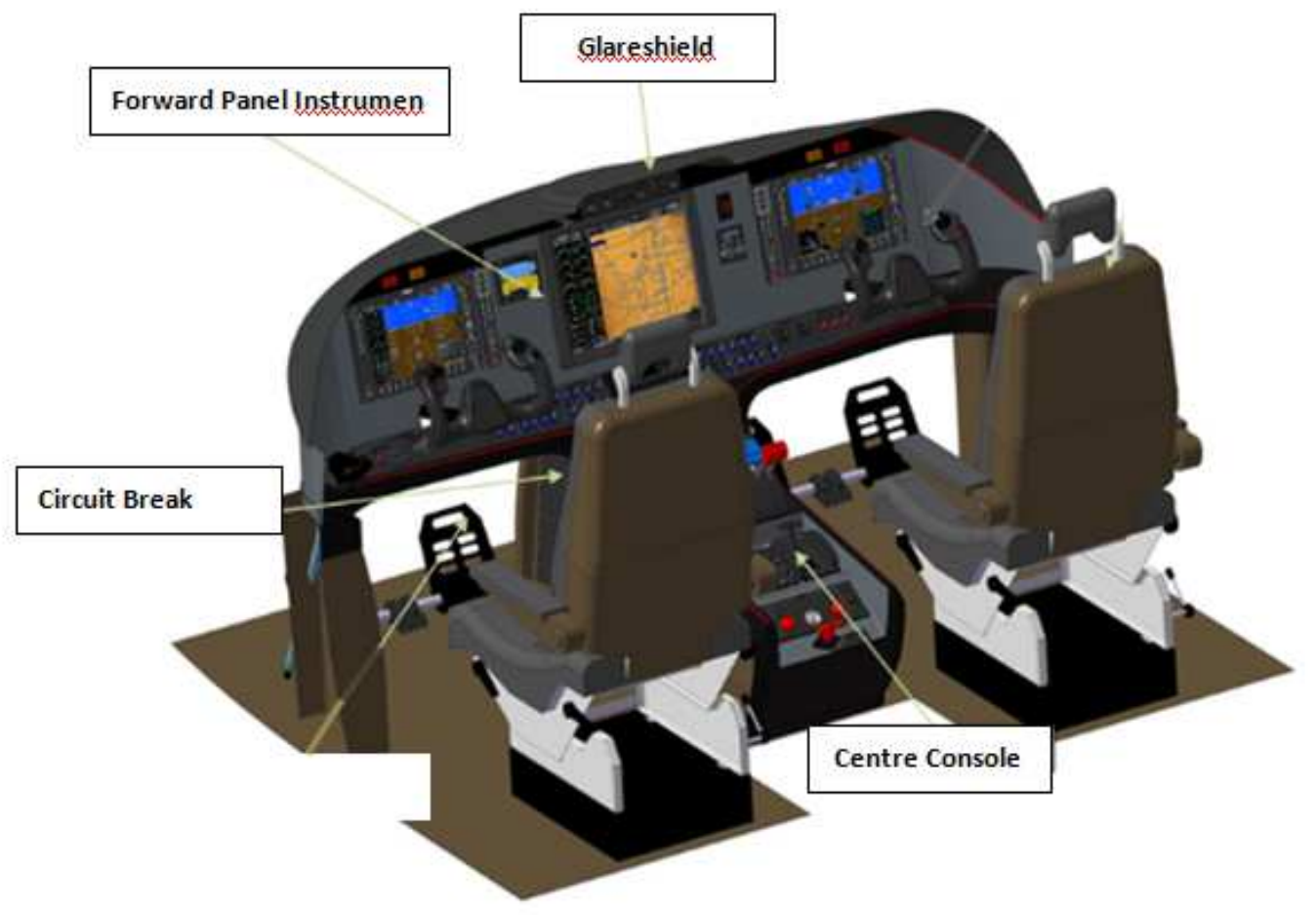

Gambar 2.

DetailLayout Dari Tiap Panel Yang Menunjukkan Letak Instrumen, Kontrol, Dan Warning

\section{Ketentuan Tentang Kokpit}

Berdasarkan Civil Aviation Safety Regulation (CASR) $23^{8}$ terdapat beberapa ketentuan atau regulasi yag harus diikuti, diantaranya adalah:

- Ruangan (kokpit) dan peralatan yang terdapat di dalam kokpit harus dapat menunjang tugas pilot tanpa mengganggu konsentrasi dan kelelahan pada pilot.

- Pandangan dari Kokpit

a) Kokpit harus didesain dengan pandangan (view) yang luas, jelas, dan tidak berbias sehingga pilot dapat melakukan tugasnya (taxi, takeoff, approach, land, maneuvers) dengan aman.

b) Kokpit harus didesain bebas dari cahaya yang menyilaukan dan pantulan cahaya yang dapat mengganggu pandangan pilot.

c) Kokpit harus didesain ketika terjadi hujan tidak menghalangi pandangan pilot ketika penerbangan dalam kondisi normal maupun ketika mendarat
- Cockpit Control

a) Kontrol pada kokpit harus dapat diidentifikasi oleh pilot sehingga pilot dapat merasa nyaman. Hal ini untuk menghindari kebingungan dan kelalaian oleh pilot dalam memnjalankan tugasnya.

b) Kontrol pada kokpit harus disusun atau didesain agar tidak terhalang apapun ketika pikot duduk pada kursi.

\section{Tahapan Pilot dalam Menerbangkan Pesawat}

Secara umum, menerbangkan pesawat dibagi menjadi 4 tahap ${ }^{10)}$, yaitu:

1) Pre-Flight (Persiapan Terbang), tahap untuk menghidupkan berbagai sistem di pesawat untuk persiapan lepas landas.

2) Take Off (Lepas Landas), tahap ketika sistem pesawat sudah menyala dan pesawat akan lepas landas dari landasan.

3) Cruise (Melaju)tahap pesawat melaju ke tujuan tertentu.

4) Landing (Mendarat), tahap pesawat kembali menyentuh landas pacu dan kemudian berhenti. 
Evaluasi Ergonomi Kokpit Pesawat Udara N-219 Dengan Usability Testing (Triyono Widi Sasongko, Nina Kartika, Tegar Septyan, Dimas Bahtera E, Budi Sampurno)

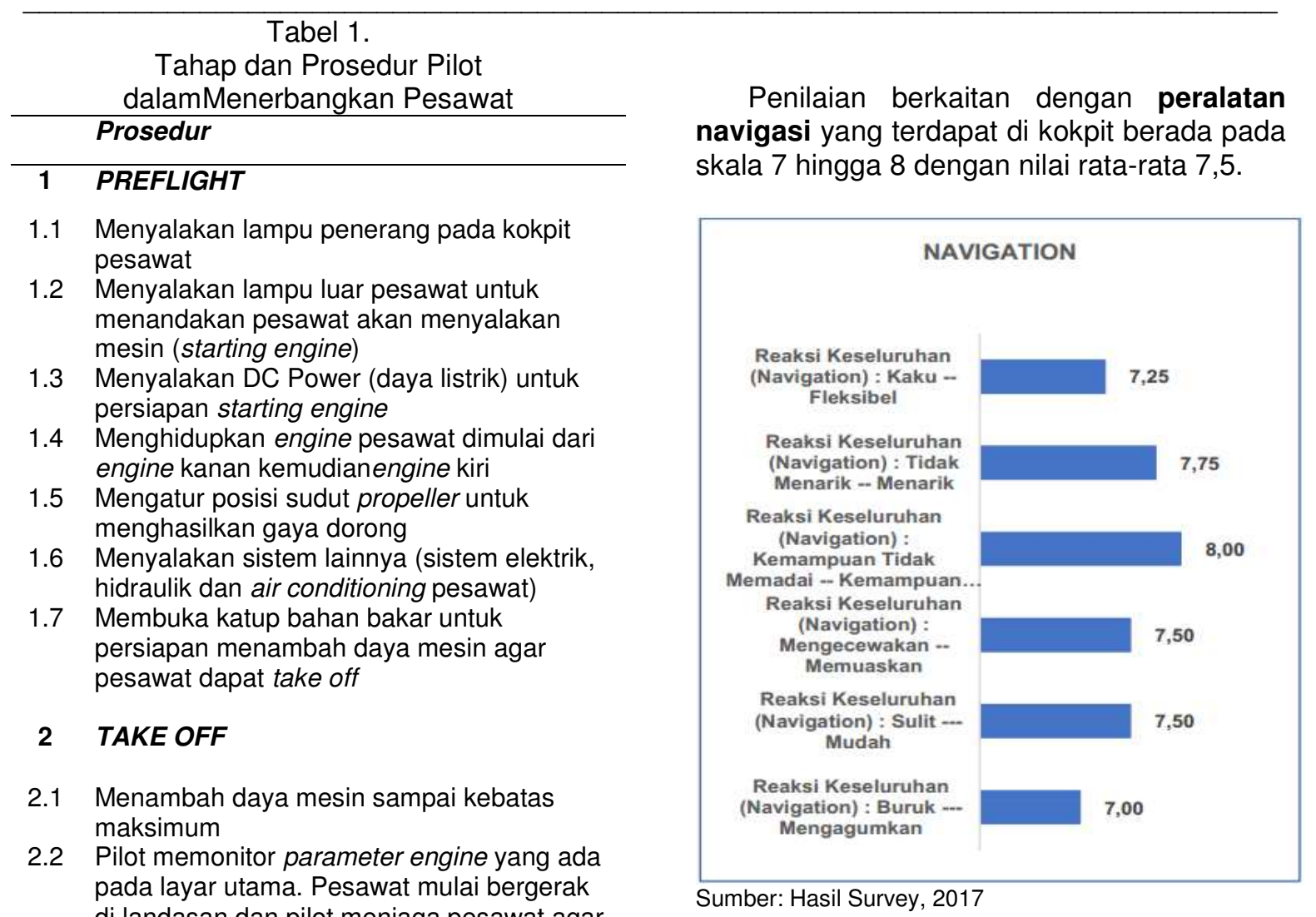
di landasan dan pilot menjaga pesawat agar tetap pada jalurnya dengan mengendalikan setir (Control Wheel)

2.3 Setelah mencapai kecepatan tertentu, pilot mulai melepaslandaskan pesawat pesawat dengan menarik control wheel

2.4 Menyesuaikan daya mesin keposisi cruise

\section{CRUISE}

3.1 Pilot mengemudikan dan mengarahkan pesawat ke tujuan dengan menggunakan control wheel. Sesekali pilot mengatur daya mesin pesawat.

\section{LANDING}

4.1 Mengatur flap pada posisi landing dan menurunkan daya mesin untuk persiapan landing.

4.2 Pilot mengarahkan pesawat menuju landasan dan kemudian mendarat.

4.3 Melakukan power reverse (membalikkan arah dorong pesawat dengan mengatur sudut propeller) untuk memperlambat laju pesawat hingga berhenti.

Sumber: PT Dirgantara Indonesia, 2016

\section{Hasil Survey Questionnaire For User Interaction Satisfaction (QUIS)}

- Reaksi Keseluruhan Terhadap Sistem (Navigasi, Komunikasi, Propulsi, Elektrikal, Environmental dan Flight Control)

\section{Gambar 3}

Reaksi Keseluruhan Terhadap Sistem (Navigation)

Penilaian berkaitan dengan peralatan komunikasi yang terdapat di kokpit berada pada skala 7,25 s/d 7,75 dengan nilai ratarata 7,58 .

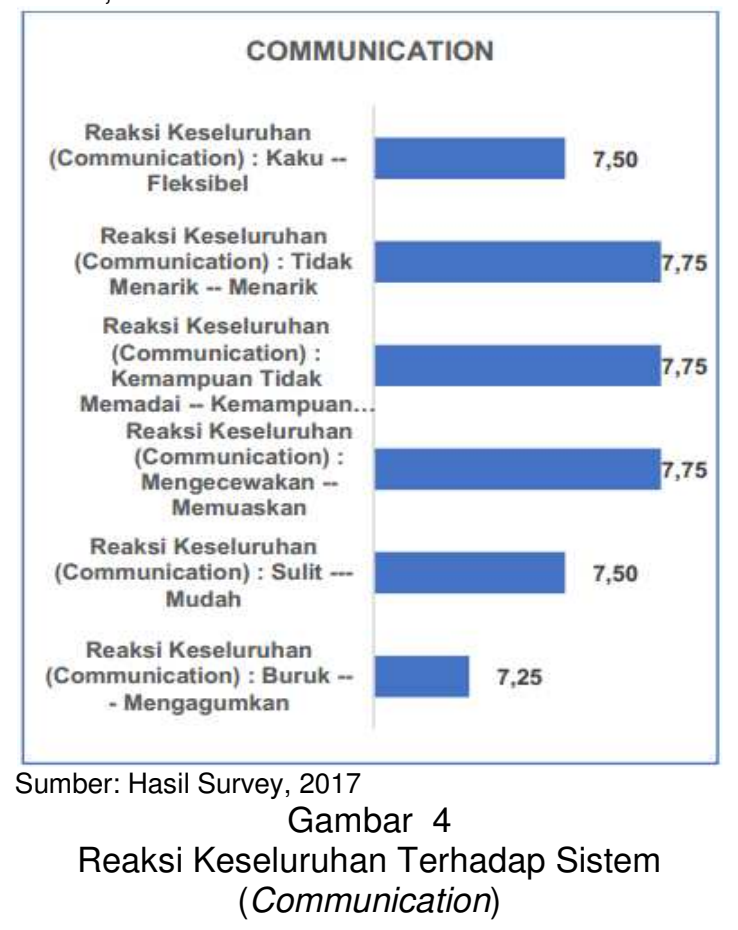


Penilaian berkaitan dengan peralatan terkait propulsi yang terdapat di kokpit berada pada skala $7 \mathrm{~s} / \mathrm{d} 8,25$ dengan nilai rata-rata 7,71 .

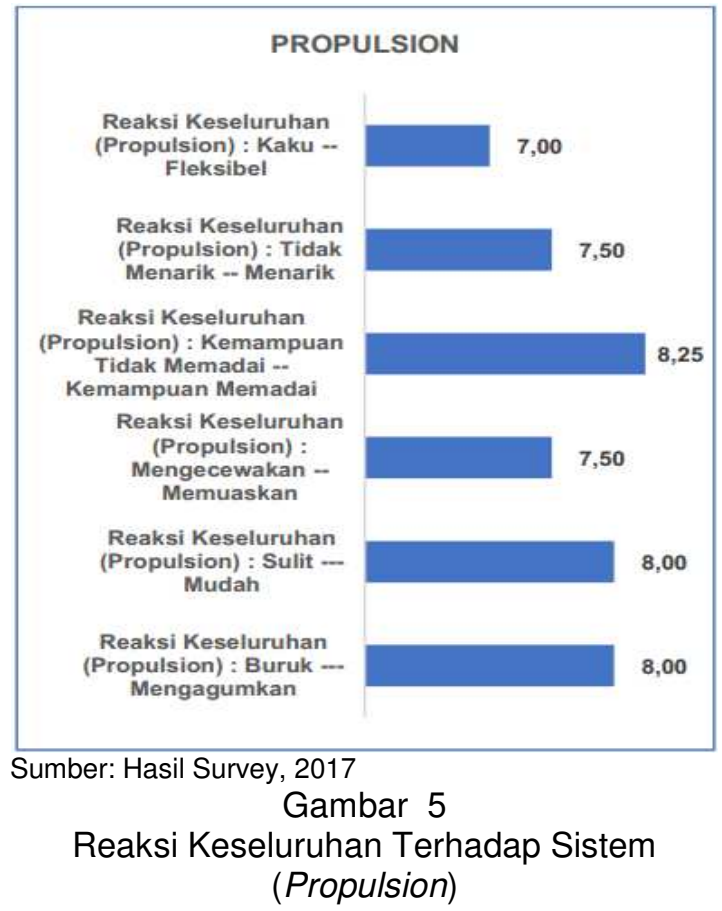

Penilaian berkaitan dengan peralatan terkait electricalyang terdapat di kokpit berada pada skala $6,5 \mathrm{~s} / \mathrm{d} 8$ dengan nilai ratarata 7,38 .

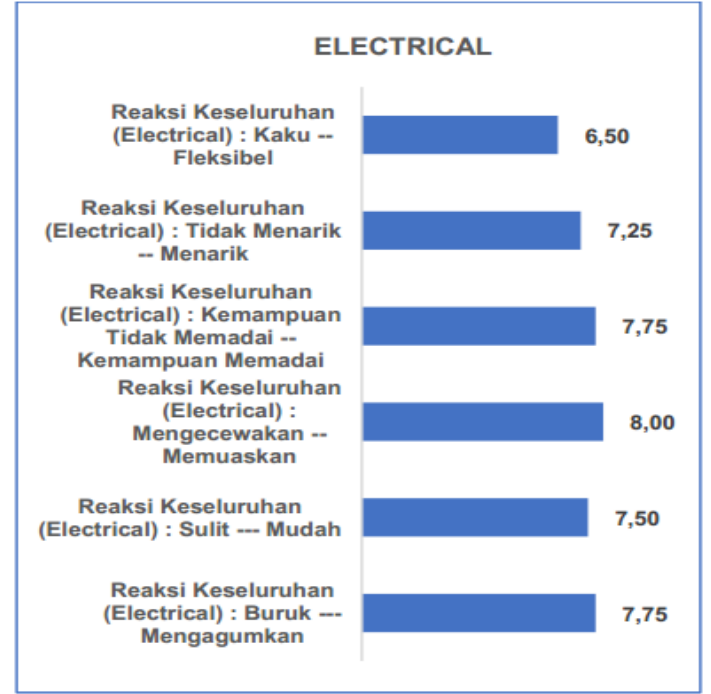

Sumber: Hasil Survey, 2017

Gambar 6

Reaksi Keseluruhan Terhadap Sistem (Electrical)

Penilaian berkaitan dengan peralatan terkait environmental yang terdapat di kokpit berada pada skala $6,33 \mathrm{~s} / \mathrm{d} 8$ dengan nilai rata-rata 6,95.

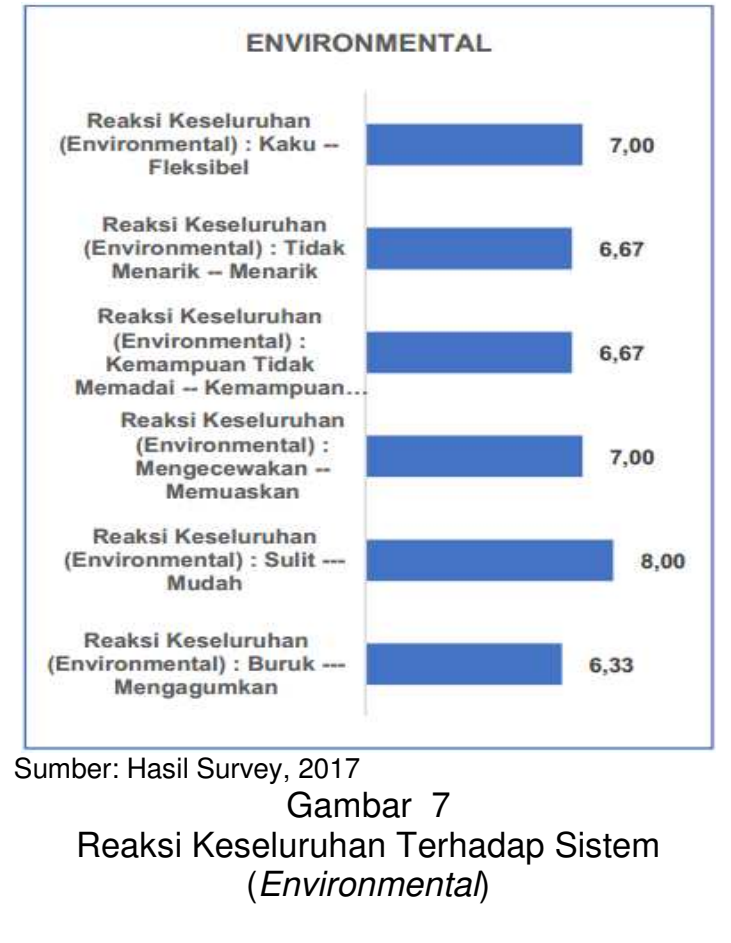

Penilaian berkaitan dengan peralatan flight controlyang terdapat di kokpit berada pada skala $6,25 \mathrm{~s} / \mathrm{d} 7,25$ dengan nilai ratarata 6,75 .

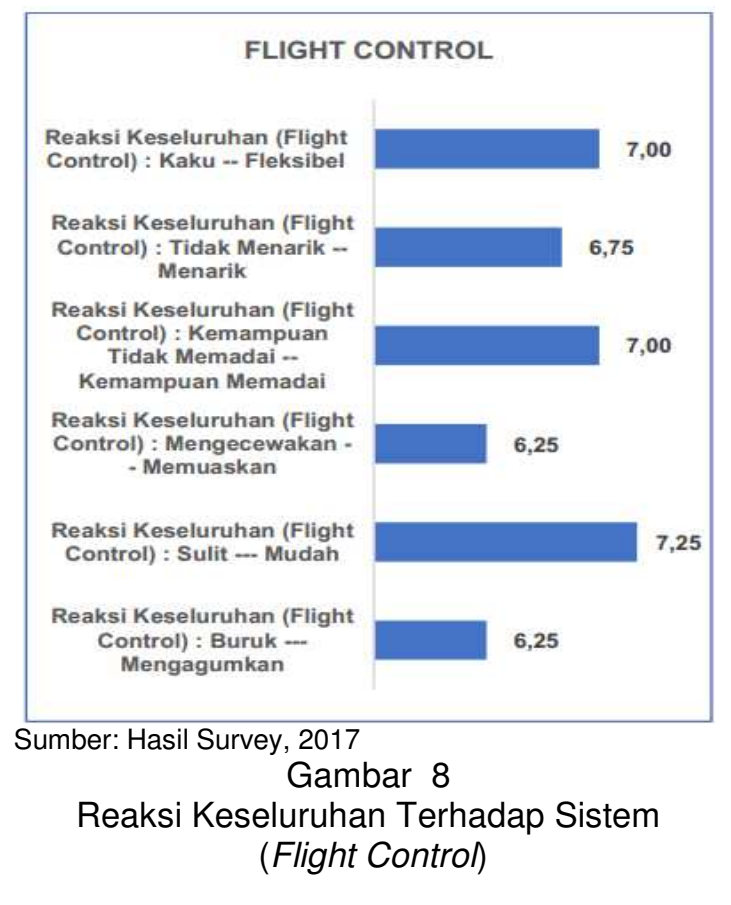

\section{- Reaksi Terhadap Display}

Penilaian berkaitan dengan Primary Flight Display (PFD)yang terdapat di kokpit berada pada skala 8,00 s/d 8,50 dengan nilai rata-rata 8,19 . 
Evaluasi Ergonomi Kokpit Pesawat Udara N-219 Dengan Usability Testing (Triyono Widi Sasongko, Nina Kartika, Tegar Septyan, Dimas Bahtera E, Budi Sampurno)

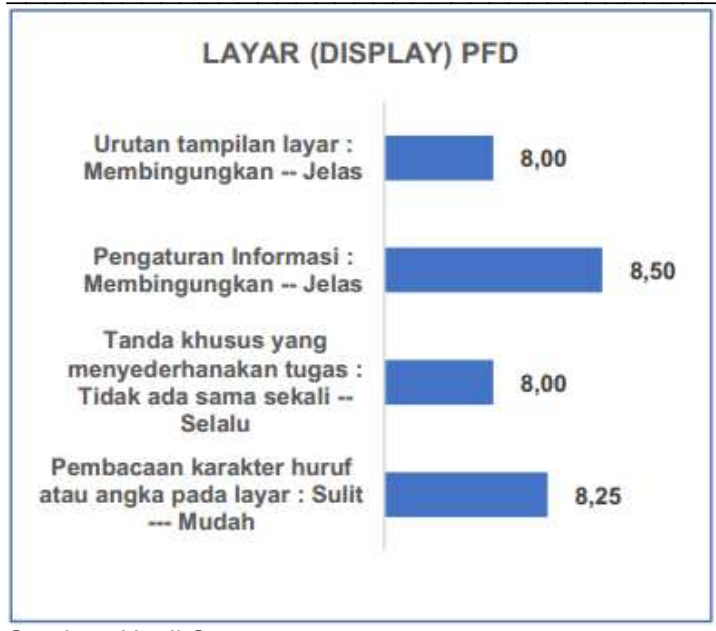

Sumber: Hasil Survey, 2017

\section{Gambar 9}

Reaksi Terhadap Layar (Display) PFD

Penilaian berkaitan dengan MultiFunction Flight Display (MFD)yang terdapat di kokpit mempunyai nilai sama dengan PFD, yang berada pada skala $8,00 \mathrm{~s} / \mathrm{d} 8,50$ dengan nilai rata-rata 8,19 .

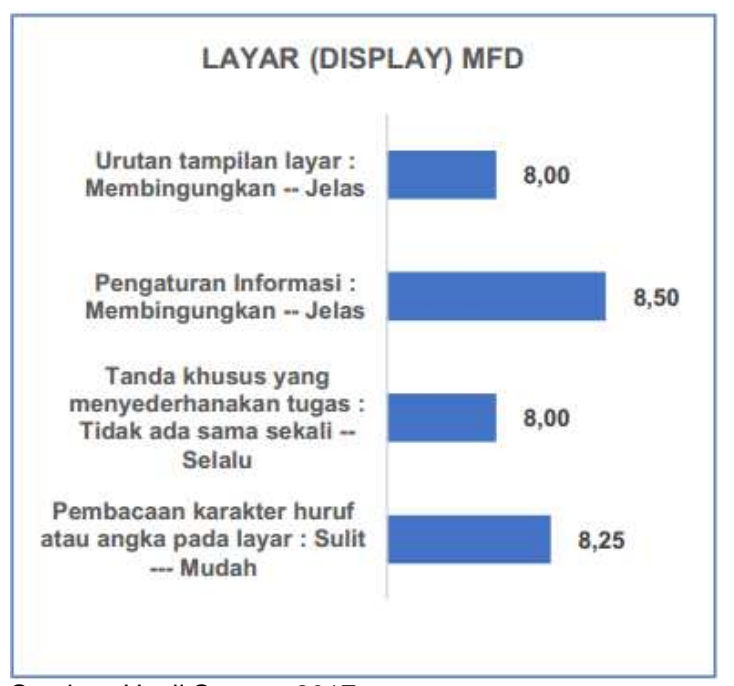

Sumber: Hasil Survey, 2017

\section{Gambar 10}

Reaksi Terhadap Layar (Display) MFD

\section{- Reaksi Terhadap Teknologi dan Sistem Informasi}

Penilaian berkaitan dengan teknologi dan sistem informasi yang terdapat di kokpit berada pada skala $6,5 \mathrm{~s} / \mathrm{d} 8,5$ dengan nilai rata-rata 7,88 .

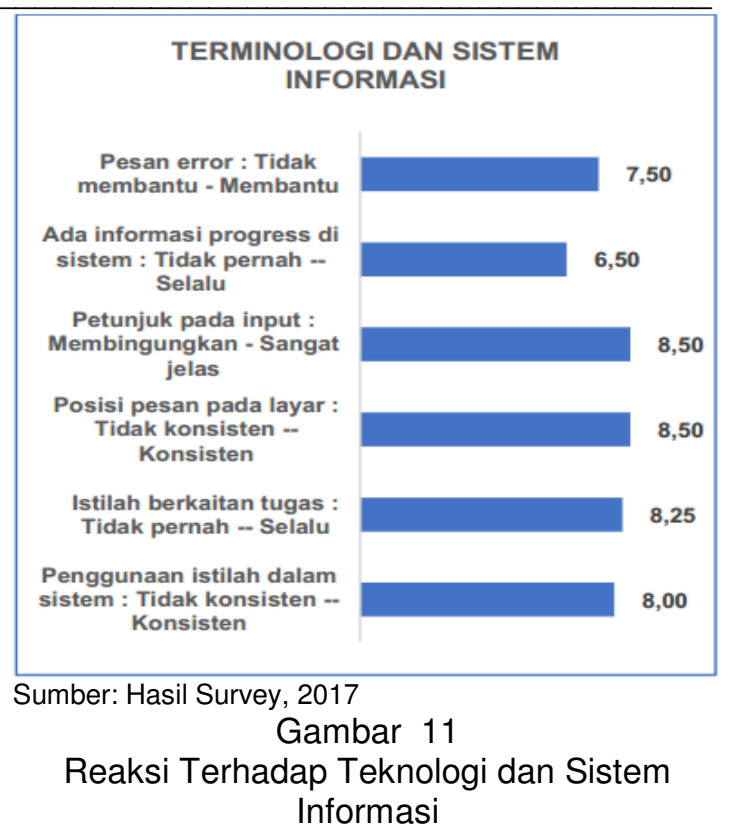

\section{- Reaksi Terhadap Pembelajaran}

Penilaian berkaitan dengan aspek pembelajaran berada pada skala $6,5 \mathrm{~s} / \mathrm{d} 8$ dengan nilai rata-rata 7,5 .

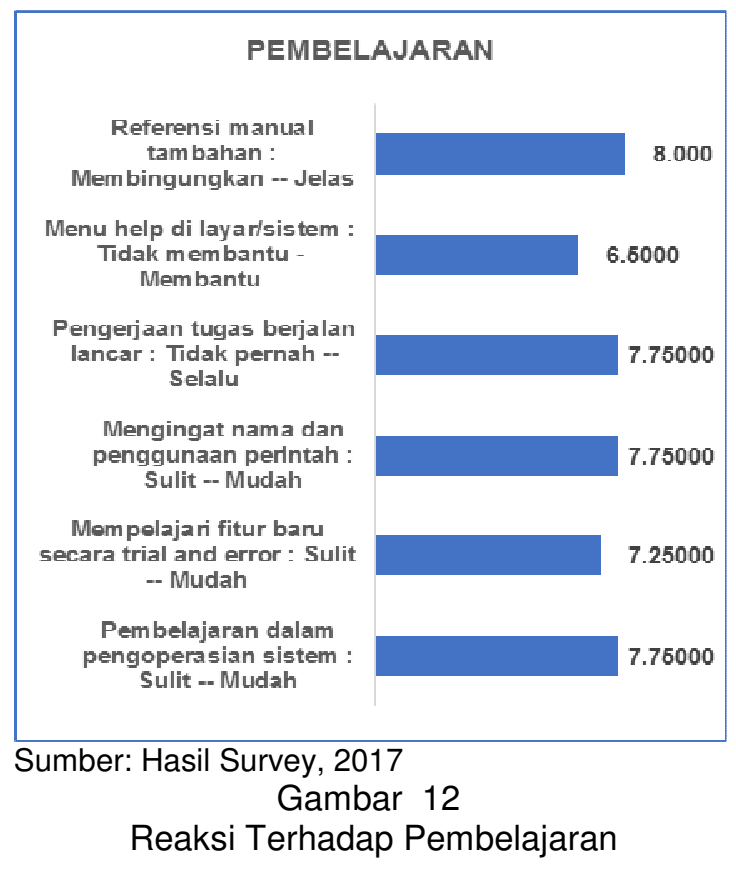

- Reaksi Terhadap Kapabilitas Sistem

Penilaian berkaitan dengan kapabilitas sistem yang terdapat di kokpit berada pada skala $7 \mathrm{~s} / \mathrm{d} 8,5$ dengan nilai rata-rata 7,8 . 


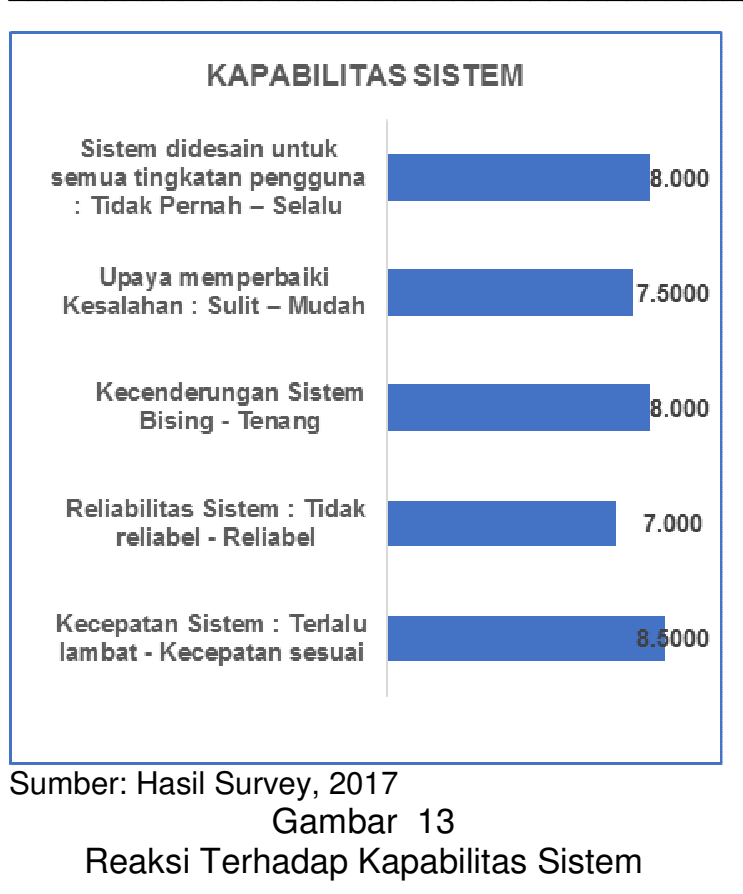

\section{- Perbandingan 5 Aspek Utama pada Kuesioner QUIS}

Berikut ini merupakan perbandingan nilai rata-rata dari 5 aspek utama yang telah dipaparkan di atas, dimana aspek layar mempunyai nilai rata-rata tertinggi, kemudian diikuti pada urutan berikutnya aspek terminologi dan sistem informasi, kapabilitas sistem, aspek pembelajaran, dan aspek reaksi keseluruhan pada sistem.

Tabel 2

Perbandingan 5 Aspek Utama pada Kuesionair QUIS

\begin{tabular}{lcc}
\hline \multicolumn{1}{c}{ Aspek QUIS } & Rata-rata & $\begin{array}{c}\text { Standar } \\
\text { Deviasi }\end{array}$ \\
\hline Reaksi Keseluruhan & 7,32 & 0,84 \\
pada Sistem & 8,19 & 0,74 \\
Layar (Display) & 7,88 & 1,15 \\
Terminologi dan Sistem & 7,50 & 0,93 \\
Informasi & 7,80 & 0,89 \\
Pembelajaran & \\
Kapabilitas Sistem & \multicolumn{2}{l}{}
\end{tabular}

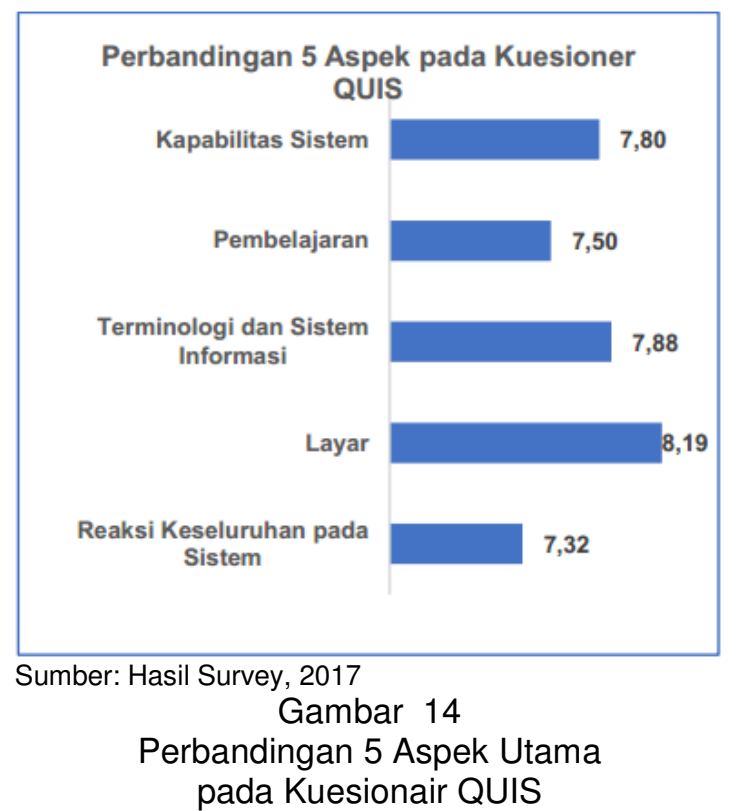

Dari Tabel 2 yang divisualkan dalam Gambar 14 dapat dilihat bahwa hanyaaspek layar (display) mempunyai rata-rata nilai 8,32, di antara nilai 8 dan 9 , yang berarti masuk dalam kategori sangat bagus (Excellent). Sedangkan aspek-aspek lainnya mempunyai nilai rata-rata nilai di antara 7 dan 8, masuk dalam kategori bagus (Good). Hasil ini secara umum mengindikasikan bahwa kondisi ergonomi kokpit $\mathrm{N}-219$ bisa diterima (Acceptable).

\section{Hasil Wawancara}

Untuk mengkonfirmasi dan memverifikasi hasil dari kuesioner yang telah diajukan, langkah selanjutnya adalah melakukan wawancara pada aircrew untuk mengakomodasi masukan dan catatan yang belum terwadahi dalam butir pertanyaan di kuesioner. Untuk wawancara, jumlah sampel untuk responden adalah sebanyak sampel pada kuesioner ditambah 2 orang pilot yang mewakili variasi dari persentil bawah sampai persentil atas.

Beberapa catatan yang berkaitan dengan hasil diskusi terhadap para aircrew adalah lebih banyak melakukan benchmarking/membandingkan dengan kokpit pesawat lainnya yang sekelas.

Aspek-aspek positif:

1) Secara umum penempatan/posisi instrument sudah baik dan sudah sesuai standar, tidak membingungkan pilot

2) Untuk fitur pembelajaran juga relatif sudah baik, tetapi tetap dibutuhkan adanya semacam menu yang bisa berperan sebagai menu bantuan untuk pengoperasian 
Evaluasi Ergonomi Kokpit Pesawat Udara N-219 Dengan Usability Testing (Triyono Widi Sasongko, Nina Kartika, Tegar Septyan, Dimas Bahtera E, Budi Sampurno)

3) Untuk pengaksesan menu secara umum relatif baik, tetapi untuk menu tertentu (apabila memungkinkan) ada proses/langkah yang bisa diefisienkan

Aspek-aspek lainnya yang bisa ditingkatkan:

1) Kokpit yang bisa diakomodasikan untuk pilot yang memiliki tubuh di atas rata-rata karena secara umum sistem yang berjalan saat ini masih kurang nyaman bagi pilot yang memiliki persentil atas

2) Pengembangan software tidak hanya menggunakan pengaturan bawaaan dari provider, tetapi juga mengakomodasi kebutuhan yang ada (pengembangan bisa bersifat open) apabila ingin dimodifikasi untuk tujuan efisiensi dan efektifitas pengoperasian

3) Untuk penanda tombol, hal yang bisa ditingkatkan adalah adanya warna yang berbeda selain perbedaan bentuk, hal ini akan memudahkan pilot untuk mengoperasikan tombol secara intuitif.

\section{SIMPULAN}

Hasil survey pengukuran ergonomic kognitif dengan metode pengukuran usability denganQuestionnaire for User Interaction Satisfaction (QUIS), yang meliputi reaksi aircrew terhadap keseluruhan sistem, display, teknologi system informasi, pembelajaran dan kapabilitas sistem di kokpit $\mathrm{N}-219$ mempunyai nilai pada skala 7,32 s/d 8,19 , dengan kategori baik dan bisa diterima, meskipun terdapat beberapa kekurangan yang harus diperbaiki.Berdasarkan persepsi pilot bisa disimpulkan bahwa:Secara umum penempatan/posisi instrument sudah baik dan sudah sesuai standar, tidak membingungkan pilot.Untuk fitur pembelajaran juga relatif sudah baik, tetapi tetap dibutuhkan adanya semacam menu yang bisa berperan sebagai menu bantuan untuk pengoperasian.Untuk pengaksesan menu secara umum relatif baik, tetapi untuk menu tertentu (apabila memungkinkan) ada proses/langkah yang bisa diefisienkan.Salah satu titik kritis yang perlu menjadi catatan adalah pengembangan desain kokpit pesawat ini ke depannya perlu mengakomodasi pilot yang memiliki antropometri persentil atas apalagi bila pesawat ini ingin dikomersialisasikan kepada maskapai yang memiliki armada pilot asing (umumnya memiliki ukuran tubuh persentil atas).

\section{UCAPAN TERIMA KASIH}

Terima kasih kami sampaikan kepada Kemenristekdikti yang telah membiayai penelitian ini melalui program Insinas Ristek Tahun 2016 dan 2017.

\section{DAFTAR PUSTAKA}

1. Triyono Widi Sasongko, Nina Kartika, Tegar Septyan, Dimas Bahtera E,Analisis Ergonomi Konfigurasi Kokpit Pesawat Udara N-219, Prosiding Seminar Perhimpunan Ergonomi Indonesia, Denpasar, Oktober 2017.

2. Nielsen, J, Usability Engineering, Morgan Kaufmann, 1993.

3. Lewis, J,Sample Sizes for Usability Studies: Additional Considerations., Human Factors, 1994.

4. Nielsen,J, \& Landauer, T, A Mathematical Model of the Finding of Usability Problems, ACM Proceedings, Interchi 93, Amsterdam, 1993.

5. Virzi, R, Refining the Test Phase of Usability Evaluation: How Many Subjects is Enough?, Human Factors, 1992.

6. Tarwaka, Solichul HA.Bakri, Lilik Sudiajeng, Ergonomi untuk Keselamatan, Kesehatan Kerja dan Produktivitas, Uniba Press, 2004.

7. Kuswana, Wowo Sunaryo, Ergonomi dan Kesehatan Keselamatan Kerja (K3), Rosdakarya, Bandung, 2016.

8. International Civil Aviation Organization, 'Safety Report2014 Edition.

9. Zhang, Yanjun et al, A Framework for Ergonomics Design of Transport Category Airplane Cockpit, ISAA, Procedia Engineering, 2013.

10. Zhongsheng Wang, Study of Evolution Mechanism on Aircraft Sudden Failure, 2011. 
